\title{
Electronic Library for Scientific Journals: Consortium Project in Brazil
}

Making information available for the acquisition and transmission of human knowledge is the focal point of this paper, which describes the creation of a consortium for the university and research institute libraries in the state of São Paulo, Brazil. Through sharing and cooperation, the project will facilitate information access and minimize acquisition costs of international scientific periodicals, consequently increasing user satisfaction. To underscore the advantages of this procedure, the objectives, management, and implementation stages of the project are detailed, as submitted to the Research Support Foundation of the State of São Paulo (FAPESP).

\section{Production, Organization, and Acquisition of Knowledge}

In 1851, predicting the imminent growth in information, which in fact exploded in volume one hundred years later, Joseph Henri of the Smithsonian Institute voiced his opinion that the progress of mankind is based on research, study, and investigation, which generate wisdom, knowledge or, simply, information. He stated that for practically every item of interest there is some record of knowledge pertinent to it, "and unless this mass of information be properly arranged, and the means furnished by which its content may be ascertained, literature as well as science will be overwhelmed by their own unwieldy bulk. The pile will begin to totter under its own weight, and all the additions we may heap upon it will tend to add to the extension of the base, without increasing the elevation and dignity of the edifice."1

At the threshold of the twenty-first century, these words become more self-evident by the day. There are enormous archives of knowledge from which people extract parts, allowing them to advance and progress in science, technology, and the humanities. Until some decades back, recovery from these archives was essentially a manual task consisting of written work and organization. Today's technologies provide auxiliary tools to transmit this knowledge.

Although information is a cultural and social asset, it now is purchased at high prices. Making these enormous archives available in a clear and organized manner by using the proper technology is currently the greatest challenge for all those involved in knowledge management-the production, organization, and transmission of information.

\section{The Advent and Implications of Electronic Publications}

Among the major contributions of the industrial era, outstanding are the evolution and growth of information publishing and printing facilities that use tools to record, store, and distribute information. In the last ten years, the first steps were taken toward the storage and reproduction of sounds and images in new multimedia formats.

Technological advances also have brought new possibilities in accessing and disseminating information. Electronic publishing has been particularly effective in accelerating access and contributing to the generation of additional knowledge; consequently, an exponential increase in data has taken place, most notably in the second half of the twentieth century. Current journals numbered about 10,000 at the beginning of the century; by the year 2000 the number had reached an estimated 1 million.?

As a result, specialized literature has been warning about a possible crisis in the traditional system of scientific publications on paper. In addition to the difficulty of financing the publication of these works, the prices of subscriptions to scientific periodicals on paper have been rising every year. At times, this makes it impracticable to update collections in all libraries, which interferes substantially in development.

On the other hand, access to electronic scientific publications via Internet is proving to be an alternative for maintaining these collections at lower cost. It also provides greater agility in publishing and distributing the periodical, and in the final user's accessing of the information. Due to this, it is important that institutions that wish to support and promote research developed by their scientific communities facilitate access to these publications on electronic media.

To paraphrase Line, we can say that although publishers are still uncertain as to all the aspects of transmitting information electronically, because authors and institutions will be increasingly able to distribute their works on the Web without the direct involvements of publishers, there is an escalation in electronic publications being published by scientific publishers. ${ }^{3}$

Rosaly Favero Krzyzanowski is Technical Director of the Integrated Library System of the University of São PauloSIBi/USP, Brazil.

Rosane Taruhn is Director of the Development and Maintenance of Holdings Service of the Technical Department of the University of São Paulo-SIBi/USP, Brazil. 


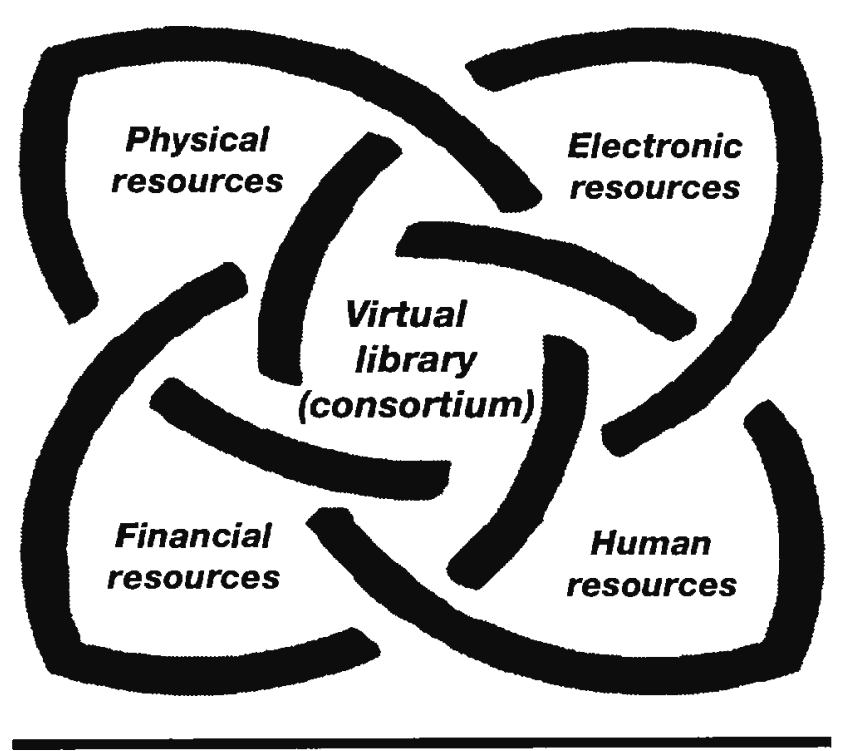

Figure 1. Infrastructure Resources for Consortium Formation

Line also says that one of the reasons for the growth in the number of electronic publications is "that it is technically possible to make them [journals] accessible in this way, and in fact easy and cheap, since nearly all text goes through a digital version on the way to publication. Secondly, journal publishers believe that electronic versions provide a second market in addition to that for their printed versions, or at least in an expanded market, since many users will be the same." 4

It is important to point out that the scientific periodical, be it paper or electronic, must ensure market value and academic community receptivity, have a staff qualified for scientific publishing, be consistent in publishing release dates, comply with international standards, and use established distribution and sales mechanisms. ${ }^{5}$

Line goes further: "Electronic publication as an 'extra' to printed publication has few added costs of journal publication other than those of printing, and publishers are not going to want to make less money from electronic journals than they do from printed ones. While printed journals once acquired can be used and reused without extra cost, each access to an electronic article has to be paid for. And although the costs of storage and binding may be saved, these are offset by the costs of printing out." ${ }^{6}$ He then notes that this technology demands an active equipment and telecommunication infrastructure.

Another point he addresses is the need for users to master the search strategies required to efficiently recover information, thus reducing the time spent and costs.

In turn, Saunders points out that, depending on the contracts made with the publishers or their agents: libraries, through their development, formation, and maintenance policies, should be receptive to this transition by accommodating the different means of communication to the different user needs and striving for a new balance. These policies should certainly stress the cooperation and sharing of remote access to the information demanded. Budget estimates should, therefore, foresee, in addition to the subscriptions to electronic titles with complete texts, other possible items like licensing rates for multi-user remote access and the right to copy articles on electronic media to paper, depending on the contracts made with the publishers or their agents.?

\section{Electronic Publication Consortiums}

Catering to mutual interests by setting up a library consortium to select, acquire, maintain, and preserve electronic information is one means of reducing or sharing costs as well as expanding the universe of information available to users and ensuring a successful outcome.

Resources-physical, human, financial, and electronic-are combined for the common good; in this case, the consortium, as shown in figure 1 , which was extracted and adapted from an OCLC Institute. ${ }^{8}$

The consortium presupposes invigoration of cooperative activities among member libraries by promoting the central administration of electronic publication databases as part of a shared library system visible to all and replete with access facilities. In addition to putting in place simplified, reciprocal lending programs and spurring the cooperative development of collections and their storing, the consortium has the objective of implementing information distribution by electronic means, provided that copyright and fair use rights are complied with. ${ }^{9}$ On the other hand, "the research library community is committed to working with publishers and database producers to develop model agreements that deploy licenses that do not contract around fair use or other copyright provisions. In this way, one seeks to insure the library practices being disseminated, especially interlibrary lending." 10

Experience shows that acquiring publications through consortia has brought great benefits and has equally favored different size institutions that would not be able to afford single subscriptions, whether on paper or in electronic format.

North American and European universities have been opting for this type of alliance to augment investment cost-benefit. Important examples of these consortia currently operative are:

- Washington Research Library Consortium, Washington, D.C., www.wric.org; 
- University System of Georgia, Galileo Project, www.galileo.peachnet.edu;

- Committee on Institutional Cooperation, Michigan, www.cedar.cic.net/cic; and

- Ohio Library and Information Network, OhioLink, www.ohiolink.ed u.

\section{The Electronic Consortium in the State of São Paulo}

Considering that Brazilian institutions also are being affected by the high cost of maintaining periodical collections and that alternative means of distributing this information are available, the model used abroad has shown itself as appropriate for developing the International Scientific Publications Electronic Library in the state of São Paulo. The location has a favorable information infrastructure available, particularly that of the electronic network of the Academic Network of São Paulo (ANSP), thanks to the support of the Research Support Foundation of the State of São Paulo (FAPESP). ${ }^{11}$

Growing user demand for direct, convenient access to information in the state of São Paulo also was a factor in location choice. The final decision was to compose the consortium of five São Paulo state universitiesUniversidade de São Paulo (USP), Universidade Estadual Paulista (UNESP), Universidade de Campinas (UNICAMP), Universidade Federal de São Carlos (UFSCAR), and Universidade Federal de São Paulo (UNIFESP)—as well as the Latin American and Caribbean Center for Health Science Information (BIREME). The consortium's goal was to make available to the member institutions' entire scientific community-10,492 faculty and researchers - rapid access to the complete, updated texts of the Elsevier Science scientific journals. This publishing house, an umbrella for North Holland, Pergamon Press, Butterworth-Einemann, and Excerpta Medica, presently publishes electronic versions of its journals.

Selection of the member institutions that would serve as a pilot group for this project was based on prior experience with the cooperative work in preparing the Unibibli Collective Catalog CD-ROM, which, using Bireme/OPAS/OMS technology, consolidates the collections of these three universities. The project was initially funded by the FAPESP; since its fourth edition the CDROM has been published through funds provided by the universities themselves, by means of a signed agreement.

Moreover, choice of Elsevier Science, which would be justified solely by its premier ranking in the global publishing market, also is due to the fact that consortium member institutions maintain subscriptions to a great number (606) of this publishing house's titles on paper.
Already fully available on electronic media, these titles are components of a representative collection initiating the building of the International Scientific Publications Electronic Library in the state of São Paulo. Furthermore, the majority of the titles are studied on the Institute of Scientific Information's Web of Science site, which has been at the disposal of researchers and libraries in the state of São Paulo since 1998.

\section{Consortium Objectives}

The consortium was formed to contribute to the development of research through the acquisition of electronic publications for the state of São Paulo's scientific community. Using the ANSP Network, in addition to augmenting and speeding up access to current scientific information in all the member institutions, will:

- increase the cost-benefit per subscription;

- promote the rational use of funds;

- ensure continuous subscription to these periodicals;

- increase the universe of publications available to users through collection sharing;

- guarantee local storage of the information acquired and thus ensure the collection's maintenance and its continual use by present and future researchers; and

- develop the technical capabilities of the personnel of the state of São Paulo institutions in operating and using electronic publication databases.

Initially, the project will not interfere in the current process of acquiring periodicals on paper and in distributing collections in member institutions. However, as electronic collection utilization becomes predominant, duplicate subscriptions to paper may be eliminated so as to allow new subscriptions to be available to the consortium at no additional cost.

\section{Implementation of the Electronic Library for International Scientific Publications}

Implementation of this project includes the following stages already achieved:

- constitution of the consortium by the six member institutions; and

- set up of an administrative board.

The following stages are in progress:

- purchase of hardware (central server) and a software manager; and

- estimate for the installation of the operational system. 

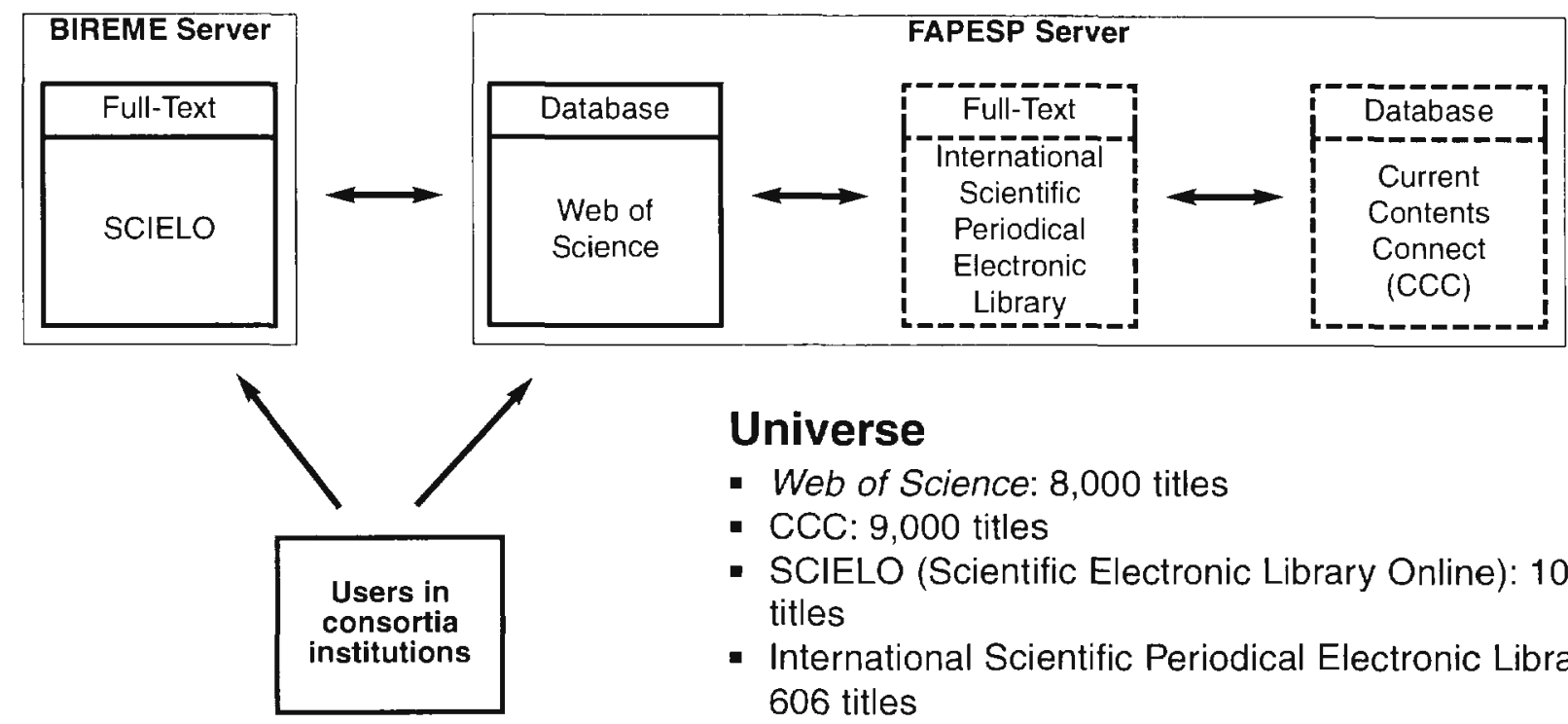

\section{Universe}

- Web of Science: 8,000 titles

- CCC: 9,000 titles

- SCIELO (Scientific Electronic Library Online): 100 titles

- International Scientific Periodical Electronic Library: 606 titles

Figure 2. Reference database and full-text interconnectivity to optimize information access

And the following stages are planned:

- training for qualified personnel and maintenance of the infrastructure built up;

- acquisition and implementation of the electronic library on the central server; and

- permanent utilization assessment.

The pilot project proposes that the central server, for storage and availability of electronic scientific periodical collections on the ANSP network, be located at FAPESP in order to facilitate development of an electronic bank. In the future, the bank should, in addition to the collection in mind for the project, include international collections of other publishing houses: the Scielo collection of Brazilian scientific magazines (Project FAPESP/Bireme) as well as the Web of Science and Current Contents Connect reference databases (see figure 2).

\section{Consortium Management}

The electronic library will be administrated by the consortium's administrative board, made up of a general coordinator, an operations coordinator, and directors and coordinators of the library systems and central libraries of member institutions as well as consultants recommended by FAPESP.

The administrative board shall be in charge of the implementation, operation, dissemination, and assessment of electronic library utilization. It also is charged with supervising qualified personnel training in order to guarantee the success of the project. An agreement specifying the consortium objective, its constitution, the manner by which it shall be executed and consortium member obligations established was signed.

Shortly, a contract to use Elsevier Science electronic publications shall be signed by FAPESP and by the provider. The agreement's documents and use license were drawn up in compliance with the principles for licensing electronic resources recommended by the American Library Association, published in final version at the 1997 American Library Association Annual Conference. ${ }^{12}$

\section{Recovery System and Information Use Evaluation}

Research on electronic media suggests that use of a single software program that offers different strategies and forms of interacting for searching the collections requires an evaluation of the efficiency of individual research strategies. This evaluation is critical for preparation of guidelines that orient the choice of systems and proper training programs. ${ }^{13}$

For the electronic library, the challenge of measuring not only the amount of file use but also the efficacy and efficiency of its information access systems and training for its users is an imperative task. In the project 
described, evaluation shall be made by indicators that demonstrate use of the electronic library and of the collections on paper, per journal title, subject researched, user institution, number of accesses per day, and user satisfaction regarding service provided (interface, response time, text copies), among other factors to be studied.

\section{Final Remarks}

The way in which electronic media are read by the users is a code far beyond the written, because sound and image are being added increasingly. In this first generation of electronic publications, FAPESP supported availability of Web of Science and of Scielo by FAPESP and the creation of the International Scientific Publications Electronic Library in the state of São Paulo. The possible introduction of Current Contents Connect will trigger an extraordinary leap in research development, facilitating the access of scientific information and the acquisition and transmission of human knowledge as well as enhancing the cooperative and sharing enterprise of member libraries.

\section{References and Notes}

1. Annual Report of the Board of Regents of the Smithsonian Institution .. During the Year 1851 (Washington, D.C. 1852), 22.

2. Leo Wieers, "A Vision of the Library of the Future," in Developing the Library of the Future: The Tilburg Experience, $\mathrm{H}$. Geleijnse and C. Grootaers, eds. (Tilburg, The Netherlands: Tilburg Univ., 1994), 1-11.
3. M. B. Line, "The Case for Retaining Printed LIS Journals," IFLA Jounal 24, no. 1 (Oct./Nov. 1998): 15-19.

4. Ibid.

5. R. F. Krzyzanowski, "Administração de Revistas Científicas," in Reunião Anual da Sociedade de Pesquisa Odontológica, Águas de São Pedro, 14, 1997. (Lecture)

6. Line, "The Case for Retaining Printed LIS Journals."

7. L. M. Saunders, "Transforming Acquisitions to Support Virtual Libraries," Information Technology and Libraries 14, no. 1 (Mar. 1995): 41-46.

8. OCLC Institute, OCLC Institute Seminar: Information Technology Trends for the Global Library Community, 1997, Ohio (Dublin, Ohio: OCLC Institute/The Andrew W. Mellon Foundation/Fundação Getúlio Vargas/Bibliodata Library Network, 1997).

9. A definition of fair use is the "legal use of information: permission to reproduce texts for the purposes of teaching, study, commentary or other specific social purposes." Found in J. S. D. O'Connor, "Intellectual Property: An Association of Research Libraries Statement of Principles." Accessed July 28, 1999, http://arl.cni.org/scomm/copyright/principles. html.

10. Statement of Current Perspective and Preferred Practices for the Selection and Purchase of Electronic Information. ICOLC Statement on Electronic Information. Accessed July 2, 1998 , www.library.vale.edu/consortia/statement.html.

11. R. F. Krzyzanowski and others, Biblioteca Eletrônica de Publicações Científicas Internacionais para as Universidades e Institutos de Pesquisa do Estado de São Paulo. São Paulo, 1998 (project presented to FAPESP_Fundação de Amparo à Pesquisa do Estado de São Paulo)

12. B. E. C. Schottlaender, "The Development of National Principles to Guide Librarians in Licensing Electronic Resources," Library Acquisitions-Practice and Theory 22, no. 1 (Spring 1998): 49-54

13. W. S. Lang and M. Grigsby, "Statistics for Measuring the Efficiency of Electronic Information Retrieval," Journal of the American Society for Information Science 47, no. 2 (Feb. 1996): 159-66. 